\title{
Microtubule Stabilization Promotes Microcirculation Reconstruction After Spinal Cord Injury
}

\author{
Yang-Yang Duan ${ }^{1} \cdot$ Yong Chai $^{1} \cdot$ Nai-Li Zhang ${ }^{1} \cdot$ Dong-Mei Zhao $^{1} \cdot$ Cheng Yang $^{1}$ (D)
}

Received: 15 May 2020 / Accepted: 5 August 2020 / Published online: 8 September 2020

(C) The Author(s) 2020

\begin{abstract}
Spinal cord microcirculation plays an important role in maintaining the function of spinal cord neurons and other cells. Previous studies have largely focused on the ability of microtubule stabilization to inhibit the fibroblast migration and promote axon regeneration after spinal cord injury (SCI). However, the effect of microtubule stabilization treatment on microcirculation reconstruction after SCI remains unclear. By using immunofluorescence, we found that microtubule stabilization treatment improved microcirculation reconstruction via increasing the number of microvessels, pericytes, and the perfused microvessels after SCI. To clarify the underlying mechanisms, rat brain microvascular endothelial cells and pericytes were subjected to glucose oxygen deprivation. By using flow cytometry and western blotting, we found that microtubule stabilization treatment inhibited apoptosis and migration of endothelial cells and pericytes but promoted proliferation and survival of endothelial cells and pericytes through upregulated expression of vascular endothelial growth factor A (VEGFA), VEGF receptor 2, plateletderived growth factor-B (PDGFB), PDGF receptor $\beta$, and angiopoietin- 1 after SCI. Taken together, this study provides evidence for the mechanisms underlying the promotion of microcirculation reconstruction after SCI by microtubule stabilization treatment. Importantly, this study suggests the potential of microtubule stabilization as a therapeutic target to reduce microcirculation dysfunction after SCI in the clinic.
\end{abstract}

Keywords Endothelial cells $\cdot$ Microcirculation $\cdot$ Microtubule $\cdot$ Pericytes $\cdot$ Spinal cord injury

\section{Introduction}

Spinal cord injury (SCI) often leads to the lifelong sensorimotor and autonomic neurological dysfunctions in the patient. The poor prognosis creates a heavy burden on both the family and society (Qiu 2009). Owing to the lack of the efficient treatment, the functional recovery after SCI remains challenging (Fitch and Silver 2008). The repairing mechanisms and functional recovery have been extensively studied. Different approaches have been tried in the past decades, for example, stem cell transplantation, tissue engineering, and gene therapy (Varma et al. 2013). However, there is still no effective method to improve functional recovery after SCI.

Electronic supplementary material The online version of this article (https://doi.org/10.1007/s12031-020-01679-5) contains supplementary material, which is available to authorized users.

Cheng Yang

yangchxn@163.com

1 Department of Anatomy, Binzhou Medical University, Yantai 264003, Shandong, China
After SCI, the local vasculature in the injured site is disrupted. Subsequent pathological changes including endothelial cell and pericyte loss, vessel density decrease, and an organization disorder that contribute to the spread and aggravation of secondary inflammation damages to the central nervous system have been reported (Mautes et al. 2000). The breakdown of microvessels promotes the entry of inflammatory cells and cytokines into the nervous system through the injury site to exacerbate neurological dysfunction. Moreover, the dysfunctional microvessels lead to apoptosis in other cells in the central nervous system, such as astrocytes, microglia, and neurons (Ling and Liu 2007; Liu et al. 1997). Recent researches have shown that the regenerating axons tend to grow in close interaction with blood vessels, which provides them with a nutritionally favorable environment for rapid growth, and that the endothelial cells could engulf myelin debris to boost the recovery after SCI (Dray et al. 2009; Zhou et al. 2019). Poor microvascular perfusion leads to dorsal column sensory axon degeneration after SCI in rats (Muradov et al. 2013). Therefore, the microvessel regeneration is beneficial for recovery after 
SCI. It has been reported that cell shape stabilization and migration adapting to the various driving forces orchestrated by the microtubules are key steps of angiogenesis (Bayless and Johnson 2011). In angiogenesis initiation, the vessel growth direction is established by the microtubule. In blood vessel formation, vesicle/vacuole trafficking along the microtubule cytoskeleton in endothelial cells appears to form tubes and provide nutrition, which depends on microtubule stabilization (Norden et al. 2016). Intact and stabilized microtubules are also crucial for maintaining the newly formed vessels (Bayless and Davis 2004; Norden et al. 2016). Furthermore, a recent study indicated that the microtubule stabilization in endothelial cells led to lumenogenesis and sufficient tissue reperfusion after ischemic injury (Li et al. 2017a).

Recently, Ruschel has demonstrated that systematic administration of epothilone B (Epo B) promotes functional recovery through microtubule stabilization after SCI (Ruschel et al. 2015). Importantly, Epo B can permeate the blood-brain barrier (Ballatore et al. 2012). Microtubule stabilizing drugs promote motor function recovery by interfering with fibroblast migration to reduce fibrotic scar and by acting on the microtubule associated protein Tau to improve intrinsic neuron growth (Ruschel and Bradke 2018; Ruschel et al. 2015; Sandner et al. 2018).

However, the role and mechanism of microtubules on the restoration of vasculature after SCI remains unclear. In this study, we investigated potential effects of stabilized microtubules in microcirculation reconstruction after SCI and their underlying mechanisms. Our results revealed that microtubule stabilization promoted angiogenesis to improve prognosis after SCI. Importantly, the microtubule stabilizing treatment may present as a novel strategy for the treatment of SCI in the clinic.

\section{Materials and Methods}

\section{Cell culture}

Rat brain microvascular endothelial cells and pericytes were obtained from iCell Bioscience Inc (Shanghai, China, RAT-iCELL-n001, RAT-iCELL-n003). Endothelial cells were cultured in Endothelial Cell Medium (10\% fetal bovine serum and $1 \%$ endothelial cell growth supplement, PriMed-iCELL-002) and kept in a humidified incubator $\left(37{ }^{\circ} \mathrm{C}, 5 \% \mathrm{CO}_{2}\right.$, and $\left.95 \% \mathrm{O}_{2}\right)$. Passages between 1 and 4 were used in all experiments. Pericytes were cultured in Pericyte Medium (2\% fetal bovine serum and $1 \%$ pericyte growth supplement, PriMediCELL-015) and kept in a humidified incubator $\left(37{ }^{\circ} \mathrm{C}\right.$, $5 \% \mathrm{CO}_{2}$, and $95 \% \mathrm{O}_{2}$ ). Passages between 2 and 4 were used in all experiments.
Oxygen and glucose deprivation (OGD) model in vitro

To mimic the ischemic and hypoxic conditions after SCI, endothelial cells and pericytes were cultured in a hypoxic condition for $15 \mathrm{~min}, 30 \mathrm{~min}$, and $60 \mathrm{~min}$. The hypoxic condition was produced by replacing normal medium with the serum-free medium without glucose (Cat. 11966-025, Gibco) and placing the plates and petri dishes in a hypoxic incubator (Modular Incubator Chamber, Brincubator). The hypoxic incubator was filled with $95 \% \mathrm{~N}_{2}$ and $5 \% \mathrm{CO}_{2}$ for 8 min before use.

\section{Extraction of tubulin fractions}

The free and polymerized tubulin fractions were isolated using a method previously described by Li et al (Li et al. 2015). Cells $\left(2 \times 10^{6}\right)$ grown in $35-\mathrm{mm}$ petri dish plates were washed twice with a microtubule stabilization buffer (MTSB, 0.1 M piperazine-N, N'-bis (PIPES), $2 \mathrm{mM}$ ethylene glycol-bis $(\beta$ aminoethylether) $N, N, N^{\prime}, N^{\prime}$-tetraacetic acid (EGTA), $2 \mathrm{mM}$ ethylenediaminetetraacetic acid (EDTA), $0.5 \mathrm{mM} \mathrm{MgCl}_{2}$, and $2 \mathrm{M}$ glycerol). The cells were incubated with MTSB + $0.1 \%$ Triton X-100 + protease inhibitor cocktail (1:200) for 30 min, and the supernatant was collected as the free tubulin fraction. The Triton X-100 insoluble fraction, corresponding to the polymerized tubulin, was then solubilized in a RIPA lysis buffer (Dalian Meilun Biology Technology Co., Ltd., China) with a protease inhibitor cocktail. Cells were lysed for $30 \mathrm{~min}$ and centrifuged at $15,000 \mathrm{~g}$ for $15 \mathrm{~min}$ at $4{ }^{\circ} \mathrm{C}$. The polymerized and free tubulin fractions were quantified using western blotting analysis.

\section{Western blotting}

Free and polymerized tubulin fractions prepared as described above were probed with anti- $\alpha$-tubulin (Abcam, ab52866, 1:5000), GAPDH (Biorbyt, bs10900R, 1:5000), and voltagedependent anion-selective channel protein 1 (VDAC, Abcam, ab154856, 1:5000). GAPDH in the supernatant was chosen as the internal control for free tubulin, and VDAC in the Triton $\mathrm{X}-100$ insoluble fraction was chosen as the control for polymerized tubulin. Whole cell lysates $\left(2 \times 10^{6}\right.$ cells $)$ and spinal cord tissues (epicenter $\pm 5 \mathrm{~mm}$ ) were prepared and analyzed. The cells and tissue homogenates were lysed for $1 \mathrm{~h}$ and centrifuged at $15,000 \mathrm{~g}$ for $15 \mathrm{~min}$ at $4{ }^{\circ} \mathrm{C}$. The content of protein was detected by BCA TM assay kit (Dalian Meilun Biology Technology Co., Ltd., China). Equal amounts of protein were loaded into the wells of the $10 \%$ SDS-PAGE gel. About 20 or $50 \mu \mathrm{g}$ of total protein from cell or tissue homogenates were loaded into each well of the SDS-PAGE gel, respectively. The cell or tissue homogenates were separated and transferred to PVDF membranes (Millipore, USA). The membranes were blocked in Tris-buffered saline and Tween 
20 (TBST) containing 5\% non-fat skimmed milk for $2-3 \mathrm{~h}$ at room temperature. The following antibodies were used for immunoblotting: vascular endothelial growth factor A (VEGFA, Abcam, ab1316, 1:200), VEGF receptor 2 (VEGFR2, Abcam, ab39256, 1:1000), platelet-derived growth factor-B (PDGFB, Abcam, ab178409, 1:1000), PDGF receptor $\beta$ (PDGFR $\beta$, Abcam, ab32570, 1:1000), and angiopoietin-1 (Ang-1, Abcam, ab183701, 1:10000), and Tie-2 (Novus, NBP2-20637, 1:500). As a loading control, GAPDH was probed and normalized. The membranes were incubated with above mentioned antibodies for $12-14 \mathrm{~h}$ at 4 ${ }^{\circ} \mathrm{C}$. The immunocomplexes were determined by incubating with appropriate horseradish peroxidase-conjugated secondary antibodies for $1 \mathrm{~h}$ at room temperature and visualized using enhanced chemiluminescence (ECL).

\section{Animals}

Female Sprague-Dawley rats weighing 240-250 g (Pengyue Laboratory Animal Breeding Co. Ltd. Jinan, China) were housed under standard 12-h light/dark condition and received food ad libitum. All procedures involving experimental animals were approved by Ethics Committee for Animal Care and Use of Binzhou Medical University in China and were performed in accordance with the Chinese Association for Laboratory Animals Sciences.

Rats were randomly arranged to the following three groups: (a) Sham + vehicle (1:1 mixture of dimethyl sulfoxide (DMSO) and saline) group (sham group, $n=54$ ), (b) SCI + vehicle (1:1 mixture of DMSO and saline) group (vehicle group, $n=54)$, and (c) SCI + Epo B group $(n=54)$. Rats were deeply anesthetized by an intraperitoneal injection of $10 \%$ chloral hydrate and underwent dorsal complete transection at the T9-10 vertebra. The animals in sham group were only subjected to laminectomy. The rats received an intraperitoneal injection of Epo B at $0.75 \mathrm{mg} / \mathrm{kg}$ (Dalian Meilun Biology Technology Co., Ltd., China) or vehicle at $1 \mathrm{~h}$ and 15-day post injury (Ruschel et al. 2015). The spinal cord tissues were collected at 1-day, 2-day, 7-day, and 21-day post injury. The rats were perfused transcardially with saline and rinsed thoroughly until no more blood flew out of the right atrium, followed by the fixative $4 \%$ paraformaldehyde. Spinal cords were dissected, snap frozen, and transversely sectioned at $20 \mu \mathrm{m}$ on a cryostat. The spinal cord tissues spanning $1 \mathrm{~mm}$ (injury center) and spanning 4-5 $\mathrm{mm}$ (distal injury) rostrocaudal from the transection sites were observed, respectively.

\section{Evaluation functional vessels in SCI}

Lycopersicon esculentum binds to and labels endothelial cells and therefore identifies perfused microvessels with an endothelial lining (Benton et al. 2009; Han et al. 2010; Muradov et al. 2013). Dylight 488-Lycopersicon Esculentum (lectin, Vector, Cat\#DL-1174; Vector Laboratories, Burlingame, $\mathrm{CA} ; 400 \mu \mathrm{g}$ ) was delivered systematically by retrobulbar injection 25 min prior to transcardial perfusion with saline for sacrificing the rats. The vessel function was evaluated by examining the lectin, which was circulated and bound to the vessel basal membrane and co-localized with the endothelial cell marker, rat endothelial cell antigen-1 (RECA-1), in spinal cord sections.

\section{Immunofluorescence staining}

The section slides were warmed at room temperature for $30 \mathrm{~min}$ and washed in PBS for $30 \mathrm{~min}$. The sections were permeabilized in $1 \%$ or $0.7 \%$ Triton X-100/PBS for $15 \mathrm{~min}$ and blocked in $10 \%$ normal goat serum/PBS for $4-5 \mathrm{~h}$ at room temperature. Antibodies against RECA-1 (Abcam, ab9774, 1:200), PDGFR $\beta$ (Abcam, ab32570, 1:100), and PODXL (podocalyxin like) Biorbyt, bs1345R, 1:50) were used as primary antibodies. The cells cultured on coverslips were fixed in $4 \%$ paraformaldehyde for $30 \mathrm{~min}$, permeabilized with $0.1 \%$ Triton X-100 in PBS for 25 min, and blocked in 10\% fetal bovine serum for $1.5 \mathrm{~h}$. The primary antibody used was anti- $\alpha$-tubulin (Abcam, ab7291, 1:100). The sections and cells were incubated in secondary antibodies for $1 \mathrm{~h}$ at $37^{\circ} \mathrm{C}$ and imaged using laser scanning confocal microscopy.

\section{Cell viability}

Cell Counting Kit-8 assay (CCK-8, Dalian Meilun Biology Technology Co., Ltd., China) was performed to calculate cell viability. Endothelial cells and pericytes were seeded into 96well $\left(1 \times 10^{4}\right.$ cells/well $)$ flat bottom plates with medium without Epo B (control) or medium containing different concentrations of Epo B (10 $\rho \mathrm{M}, 100 \rho \mathrm{M})$ for $24 \mathrm{~h}$. The cells were washed for three times in PBS and incubated under the OGD condition for $60 \mathrm{~min}$ (OGD $60 \mathrm{~min}$ ). CCK-8 reagents $(10 \mu \mathrm{L}$ ) were added to each well, and the cells continued to culture for another $1.5 \mathrm{~h}$ in incubator. The optical density (OD) at $450 \mathrm{~nm}$ was detected by a microplate reader.

\section{Flow cytometry analysis of cell cycle and apoptosis}

The endothelial cells and the pericytes were incubated with Epo B $(10 \rho \mathrm{M}, 100 \rho \mathrm{M})$ for $24 \mathrm{~h}$. The cells were washed three times in PBS and incubated under the OGD condition for 60 $\min$. The endothelial cells and pericytes $\left(5 \times 10^{6}\right.$ cells $)$ were washed in PBS, harvested (1000 g, $5 \mathrm{~min}$ ), and fixed with icecold ethanol overnight at $4{ }^{\circ} \mathrm{C}$. The cells were then washed in PBS, centrifuged at $2000 \mathrm{~g}$ for $10 \mathrm{~min}$, and stained with the propidium iodide $(\mathrm{PI})$ and $\mathrm{RNase} \mathrm{A}(500 \mu \mathrm{L}, \mathrm{PI}: \mathrm{RNase} \mathrm{A}=$ $1: 9)$ for $30 \mathrm{~min}$ in the dark. The cell cycle was determined by flow cytometer (BD Biosciences). Apoptosis induction in 
endothelial cells and pericytes was analyzed by Annexin VFITC apoptosis kit I (KeyGEN Biotech, KGA105). The cells $\left(5 \times 10^{6}\right.$ cells $)$ were harvested $(1000 \mathrm{~g}, 5 \mathrm{~min})$ and washed in PBS followed by treatment with $500 \mu \mathrm{L}$ binding buffer. Annexin V-FITC solution $(5 \mu \mathrm{L})$ and PI $(5 \mu \mathrm{L})$ were added and incubated for $15 \mathrm{~min}$ at room temperature. Flow cytometry was used to analyze the cells.

\section{Cell proliferation assay}

The endothelial cells and the pericytes $\left(2 \times 10^{7}\right.$ cells $)$ were incubated with Epo B (10 $\rho \mathrm{M}, 100 \rho \mathrm{M})$ for 24 h. 5-Ethynyl2'-deoxyuridine (EDU; Click-iT ${ }^{\mathrm{TM}}$ EDU Flow Cytometry Assay Kit, Invitrogen ${ }^{\mathrm{TM}}$, OR USA) was added to endothelial cells and pericytes at a final concentration of $50 \mu \mathrm{M}$ and 40 $\mu \mathrm{M}$, and the cells were incubated for further $2 \mathrm{~h}$ and $6 \mathrm{~h}$, respectively. The cells were washed three times in PBS and incubated under the OGD condition for $60 \mathrm{~min}$. Then cells ( 2 $\left.\times 10^{7}\right)$ were harvested $(1000 \mathrm{~g}, 5 \mathrm{~min})$, washed $(1 \% \mathrm{BSA}$ in PBS, $3 \mathrm{ml}$ ), fixed (Click-iT ${ }^{\mathrm{TM}}$ fixative, $100 \mu \mathrm{L}$ ), permeabilized (10\% Click-iT ${ }^{\mathrm{TM}}$ saponin-based permeabilization and wash reagent in PBS), and incubated with Click-i $\mathrm{T}^{\mathrm{TM}}$ Plus reaction cocktail ( $10 \mu \mathrm{L}$ copper protectant, $2.5 \mu \mathrm{L}$ fluorescence dye picolylazide, $50 \mu \mathrm{L}$ reaction buffer additive, and $435 \mu \mathrm{L}$ PBS) according to the manufacturer's instructions for the Click-iT ${ }^{\mathrm{TM}}$ EDU Flow Cytometry Assay Kit. Flow cytometry was performed to analyze cell proliferation.

\section{Transwell assay}

The microtubule stabilization effect on migration of endothelial cells and pericytes was evaluated using transwell chambers with an $8-\mu \mathrm{m}$ pore-sized polycarbonate filter membrane. In the Epo B group, the cells were incubated with Epo B (10 $\rho \mathrm{M}, 100 \rho \mathrm{M})$ for $24 \mathrm{~h}$. Then cells were trypsinized and suspended in serum-free medium. The cells $\left(1 \times 10^{5}\right)$ were seeded on the upper side of chamber with the serum-free medium containing Epo B (10 $\rho \mathrm{M}, 100 \rho \mathrm{M})$. The lower well was filled with normal medium containing Epo B (10 $\rho \mathrm{M}, 100$ $\rho \mathrm{M})$. After being incubated for $24 \mathrm{~h}$, the cells on the upper side of the membrane were gently removed. Then the cells that had migrated through the $8 \mu \mathrm{m}$ pores were fixed with $4 \%$ paraformaldehyde and stained with crystal violet (Dalian Meilun Biology Technology Co., Ltd., China). The migrated cells were counted in five different fields under microscope and quantified by image $\mathrm{J}$ software (NIH, Bethesda, MD, USA).

\section{Angiogenesis in vitro}

The in vitro angiogenesis in Matrigel assay was used to assess the spontaneous formation of capillary O-like structures by endothelial cells under normal and Epo B $(10 \rho \mathrm{M})$ containing conditions. The endothelial cells were treated with Epo B or medium alone for $24 \mathrm{~h}$ in 6-well plates until they reached more than $90 \%$ confluency. Then cells were trypsinized and suspended in serum-free medium. Before endothelial cells (2 $\times 10^{4}$ cells $/ 100 \mu \mathrm{L}$ ) were seeded in 96 -well plates containing serum-free media, the plates were coated with growth factorreduced Matrigel matrix (40 $\mu \mathrm{L}, \mathrm{BD}$, Bioscience, San Jose, CA, USA) and incubated for $30 \mathrm{~min}$ at $37{ }^{\circ} \mathrm{Cin} 5 \% \mathrm{CO}_{2}$ atmosphere. Once endothelial cells were added to the 96well plates, they were incubated for $4 \mathrm{~h}$, and tube formations were determined in four random fields from each well. The branch points and tube length were analyzed by Image J software (NIH, Bethesda, MD, USA).

\section{Statistical analysis}

Quantitative assessments of fluorescence intensity, the number of cells migrated in transwell assay, and the band intensity value in western blotting was obtained using Image J. Immunofluorescence images were taken at the dorsal horn or central canal of the spinal cord. Data were shown as mean \pm SD. The data were analyzed by SPSS version 19.0 statistic software package. One-way analysis of variance (ANOVA) analysis was used to compare three or four groups, while Student $t$ tests were used for two groups. $p<0.05$ was considered significance.

\section{Results}

\section{Epo B stabilizes microtubules of OGD conditioned endothelial cells and pericytes}

To determine the effects of Epo B on the microtubules of OGD conditioned endothelial cells and pericytes, $\alpha$-tubulin was examined with immunological methods. In quiescent endothelial cells and pericytes, the microtubules organized into a clear, uniformly, and relatively regular distributed lattice network, and Epo B-treated quiescent cells displayed more orderly organized microtubules (Figs. 1a and S1a). After these cells were subjected to OGD, the organization of the tubulins was disrupted and more disarranged. Moreover, the disruption of microtubules was time-dependent (Figs. 1a and S1a). After being treated with Epo B, the microtubule structure of both the endothelial cells and pericytes was more intact, with increased regularity and upregulated immunostaining intensity, and the microtubule organization recovered to the quiescent condition $(p<0.01, n=6$; Figs. $1 \mathrm{~b}$ and $\mathrm{S} 1 \mathrm{~b})$. We also detected the expression of free tubulins and polymerized tubulins in the OGD conditioned endothelial cells and pericytes by western blotting. The level of polymerized tubulin was strongly increased at all time points in both the OGD conditioned endothelial cells and pericytes treated with Epo B $(p<0.01, n=6$; 

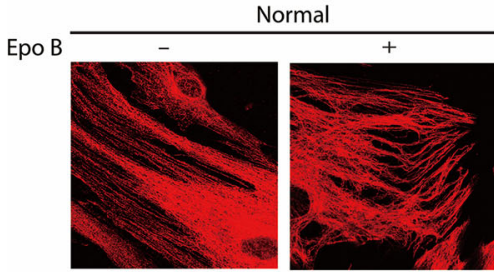

OGD $30 \mathrm{~min}$
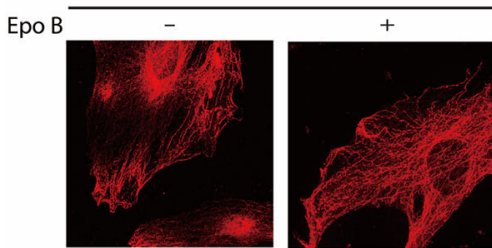

Fig. 1 Epo B stabilizes microtubule of OGD conditioned endothelial cells. a Immunofluorescence staining of $\alpha$-tubulin in endothelial cells. Scale bar $6 \mu \mathrm{m}$. b Statistical analysis of the fluorescence intensity of $\alpha$ tubulin in endothelial cells. c Immunoblotting analysis of expression of b

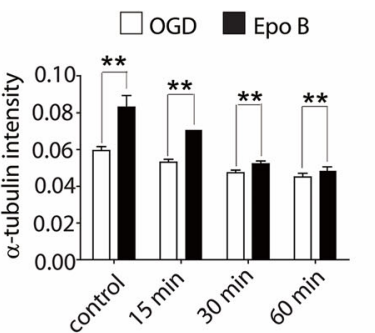

d

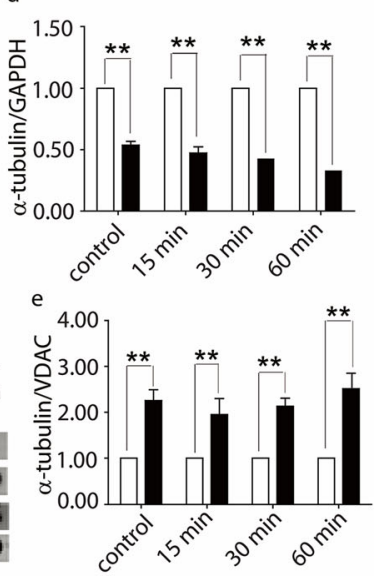

free and polymerized tubulin in endothelial cells. d-e Statistical analysis of the relative intensity of free and polymerized tubulin in endothelial cells. The data represents the mean $\pm \mathrm{SD}(n=6)$. ** $p<0.01$. Significance was determined by Student $t$ tests.

Figs. 1c, e and S1c, e). In addition, the increased free tubulin caused by OGD was reversed by Epo B treatment $(p<0.01, n$ = 6; Figs. 1c, $\mathrm{d}$ and S1c, d). These results suggest that Epo B can stabilize the microtubules of endothelial cells and pericytes.

\section{Microtubule stabilization promotes vasculature regeneration after $\mathrm{SCI}$}

To uncover the effect of microtubule stabilization on functional microvasculature after SCI, the dual staining for the injected Dylight 488-lectin and RECA-1 was performed at 21-day post injury. Our results showed that the double labeling of RECA1 and lectin in the Epo B group was significantly increased compared with that in the vehicle group $(p<0.01, n=6$; Fig. $2 \mathrm{a}-\mathrm{e})$. There was a 1.50 -fold increase of overlap ratio of RECA-1 and lectin in the injury center in the Epo B group compared with that in the vehicle group $(p<0.01, n=6$; Fig. $2 \mathrm{a}, \mathrm{c}, \mathrm{d})$. In the distal injury site, the overlap ratio in the Epo B group was increased by 1.33-fold compared with that in the vehicle group ( $p<0.01, n=6$, Fig. $2 \mathrm{~b}, \mathrm{c}, \mathrm{e})$. Our results indicate that microtubule stabilization promotes the recovery of the functional blood vessels.

To explore the mechanisms underlying the improvement in the microvessel circulation, the role of endothelial cells and pericytes in microvessel formation under the microtubule stabilization condition after SCI were examined separately. Firstly, to examine the response of the endothelial cells to microtubule stabilization, the vascular endothelial marker, RECA-1, and the lumenized vessels marker, PODXL ( $\mathrm{Li}$ et al. 2017a), were examined and quantified with immunofluorescent staining in the central and distal sites of the injury. One-way ANOVA analysis showed that the number of microvessels positive for RECA-1 in the injury center in the
Epo B group was significantly higher than that in the vehicle group, with a 3.08-fold increase at 7-day post injury and 1.50fold increase at 21-day post injury, respectively $(p<0.01, n=$ 6; Fig. 2a, c, f; Table. 1). The number of microvessels positive for RECA-1 in the distal injury site in the Epo B group increased by 3.98-fold at 2-day post injury and 2.17-fold at 7day post injury compared with that in the vehicle group ( $p<$ $0.01, n=6$; Fig. 2 b, c, g; Table. 1). To reveal the lumenogenesis after SCI, double immunofluorescence staining for PODXL and RECA-1 was used to detect the lumenized vessels. In the distal injury site at 1-day, 2-day, 7day, and 21-day post injury, the overlap ratio of RECA-1 and PODXL was $18.01 \pm 2.34 \%, 0.30 \pm 0.14 \%, 16.84 \pm 6.33 \%$, and $20.75 \pm 4.83 \%$, respectively, in the vehicle group, and $22.84 \pm 3.35 \%, 0.47 \pm 0.35 \%, 18.05 \pm 3.53 \%$, and $21.38 \pm$ $3.80 \%$, respectively, in the Epo B group (data not shown). The overlap ratio in the Epo B group was higher than that in the vehicle group, but there was no significant difference $(p>$ $0.05, n=6$ ). Secondly, to examine response of the pericytes to microtubule stabilization, the pericyte marker, PDGFR $\beta$ along with the endothelial cell marker, RECA-1, was investigated. In the injury center region, the PDGFR $\beta$ immunopositive cells in the Epo B group were $8.33 \pm 3.05$ cells $/ \mathrm{mm}^{2}$ at 7-day post injury and $13.67 \pm 1.52$ cells $/ \mathrm{mm}^{2}$ at 21-day post injury, which were significantly higher than those in the vehicle group ( $p<0.01, n=6$; Fig. 2a, c, h; Table. 1 ). In the distal injury region, the PDGFR $\beta$ immunopositive cells in the Epo B group were increased by 6.40-fold at 2 day, 2.00fold at 7 day, and 1.48-fold at 21-day post injury compared with those in the vehicle group. The PDGFR $\beta$ labeled cells were significantly increased in the Epo B group $(p<0.01, n=$ 6; Fig. 2b, c, i; Table. 1). In summary, the immunoreactivities of both the endothelial marker, RECA-1, and pericyte marker, PDGFR $\beta$ were upregulated in the SCI model with 

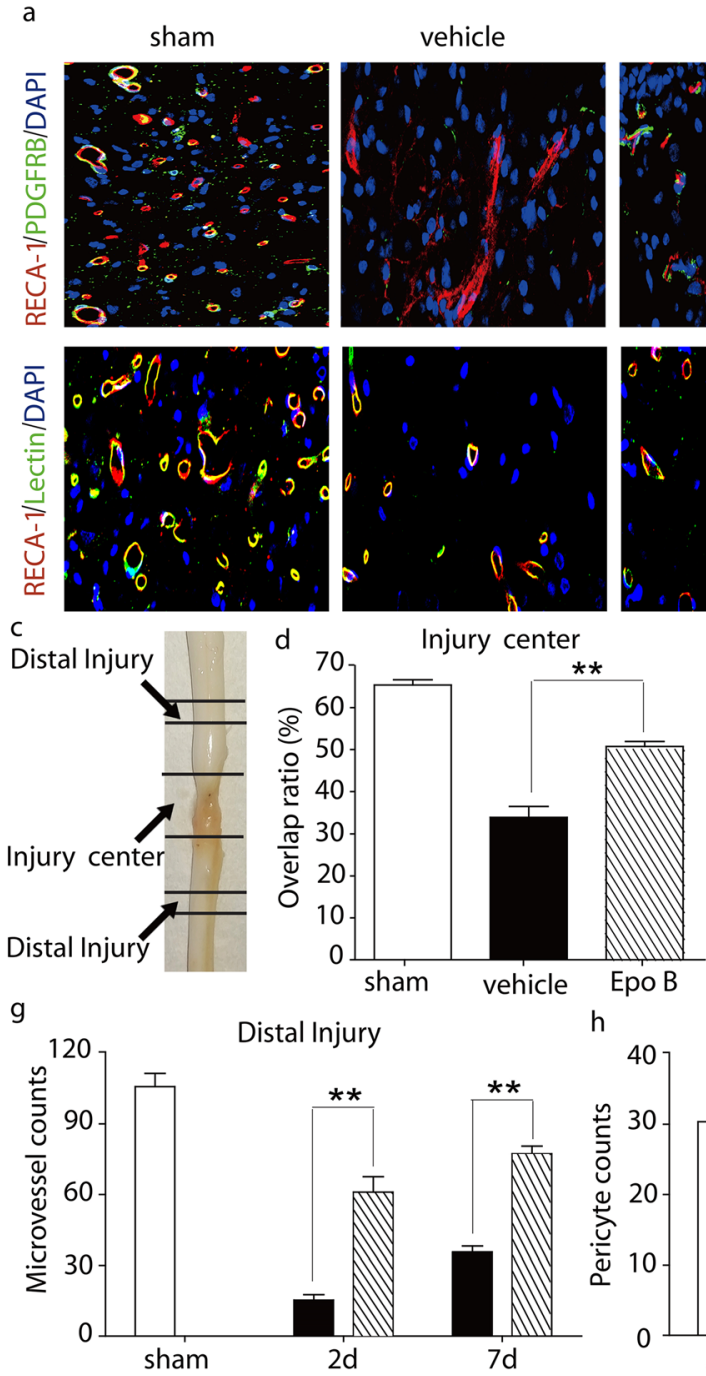

$\mathrm{h}$
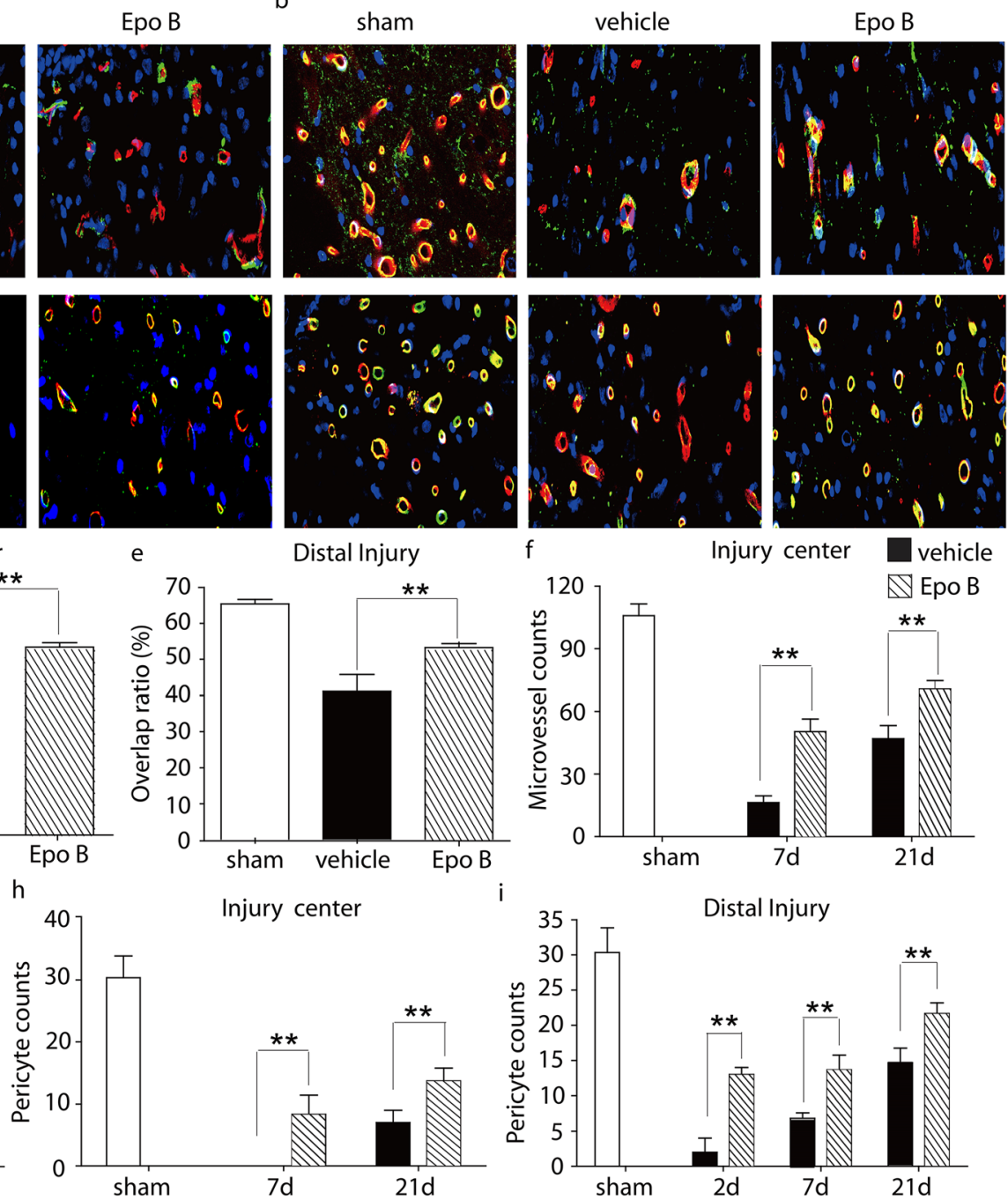

$\mathrm{f}$

Injury center
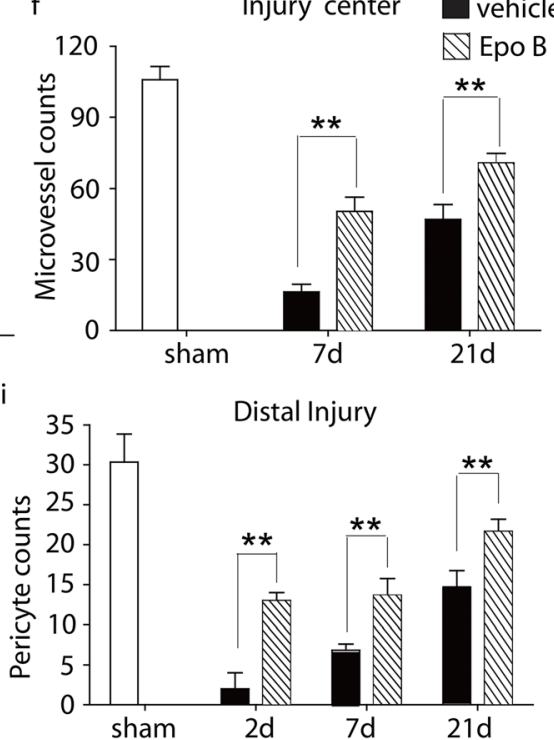

Fig. 2 Microtubule stabilization promotes the microcirculation reconstruction after SCI. a Immunofluorescence staining of RECA-1, PDGFR $\beta$, and lectin in injury center of SCI rats. Scale bar: $25 \mu \mathrm{m}$. b Immunofluorescence staining of RECA-1, PDGFR $\beta$, and lectin in distal injury of SCI rats. Scale bar: $25 \mu \mathrm{m}$. $\mathbf{c}$ The definition of injury center and distal injury sites. d-e Statistical analysis of the relative intensity of double staining of RECA-1 and lectin in SCI rats after 21-day post injury. f-g Statistical analysis of the number of microvessels positive for RECA1 in center and distal injury in SCI rats. $\mathbf{h}-\mathbf{i}$ Statistical analysis of numbers of positive PDGFR $\beta$ expressing cells in center and distal injury sites in SCI rats. Data experiments are expressed as mean $\pm \operatorname{SD}(n=6)$. ** $p<$ 0.01 . Significance is determined by one-way ANOVA followed by LSD comparison tests.

60 min conditioned endothelial cells and pericytes treated with Epo B (OGD 60-min Epo B group) was significantly higher than that in the OGD 60 min group ( $p<0.05, n=6$; Figs. $3 \mathrm{~d}$ and S3d). The percentage of endothelial cells in the resting G0/G1 phase was $80.51 \pm 1.51 \%$ in the OGD 60-min Epo B group, which was significantly lower than that in the OGD 60 min group $(84.67 \pm 0.37 \%, p<0.05, n=6$; Fig. $3 a$, f). The percentage of endothelial cells in the proliferative $\mathrm{S}$ phase was $13.53 \pm 1.11 \%$ in the OGD 60-min Epo B group, which was significantly higher than that in the OGD 60-min group (10.66 $\pm 0.56 \%, p<0.05, n=6$; Fig. 3a, f) The percentage of pericytes in the proliferative $\mathrm{S}$ phase in the OGD 60-min Epo B group was significantly higher than that in the OGD 60 -min group ( $p<0.05, n=6$; Fig. S3a, f). In the OGD 60-min 
Table 1 Microtubule stabilization promotes the reconstruction of vasculature after $\mathrm{SCI}$

\begin{tabular}{|c|c|c|c|c|}
\hline \multirow[t]{2}{*}{ Time post injury (days) } & \multicolumn{2}{|c|}{ RECA-1 (cells/mm²) } & \multicolumn{2}{|c|}{ PDGFR $\beta($ cells/mm2) } \\
\hline & $\begin{array}{l}\text { Vehicle group } \\
\text { Count }\end{array}$ & $\begin{array}{l}\text { Epo B group } \\
\text { Count }\end{array}$ & $\begin{array}{l}\text { vehicle group } \\
\text { Count }\end{array}$ & $\begin{array}{l}\text { Epo B group } \\
\text { Count }\end{array}$ \\
\hline & Injury center & & & \\
\hline 7 & $16.33 \pm 3.21$ & $50.33 \pm 6.08$ & $0.00 \pm 0.00$ & $8.33 \pm 3.05$ \\
\hline \multirow[t]{2}{*}{21} & $47.00 \pm 6.25$ & $70.67 \pm 4.04$ & $7.00 \pm 2.00$ & $13.67 \pm 2.08$ \\
\hline & Distal injury & & & \\
\hline 2 & $15.33 \pm 2.31$ & $61.00 \pm 6.55$ & $2.00 \pm 2.00$ & $13.00 \pm 1.00$ \\
\hline 7 & $35.67 \pm 2.52$ & $77.33 \pm 3.21$ & $6.83 \pm 0.77$ & $13.67 \pm 2.08$ \\
\hline 21 & $94.67 \pm 6.02$ & $97.00 \pm 5.29$ & $14.67 \pm 2.18$ & $21.67 \pm 1.52$ \\
\hline
\end{tabular}

Epo B group, the percentage of EDU labeled proliferative endothelial cells and pericytes were $10.10 \pm 0.96 \%$ and 27.27 $\pm 5.31 \%$, respectively (Figs. 3c, g and S3c, S3g); whereas in the OGD 60-min group, they were $8.10 \pm 0.69 \%$ and $17.96 \pm$ $2.25 \%$, respectively (Figs. 3c, g and S3c, g). The percentage of EDU labeled proliferative cells in the OGD 60-min Epo B group was significantly higher than that in the OGD $60 \mathrm{~min}$ group ( $p<0.05, n=6$; Figs. $3 \mathrm{c}$, g and S3c, g). These results indicate that the microtubule stabilization treatment promotes both the endothelial cells and pericytes from the G0/G1 phase to $\mathrm{S}$ phase.

Second, the apoptosis of endothelial cells and pericytes was also examined. In comparison to the OGD 60-min group, the number of live cells in the OGD 60-min Epo B group was significantly increased (Figs. $3 \mathrm{~b}$ and $\mathrm{S} 3 \mathrm{~b}$ ). In the OGD 60-min Epo B group, the apoptotic cells were significantly decreased compared with those in the OGD 60-min group $(p<0.05, n=$ 6; Figs. 3b, e and S3b, e).

Third, we also detected the effect of Epo B on lumenogenesis. The endothelial lumen formation is the first step in microcirculation regeneration. The endothelial tube formation in vitro was also quantified by counting the branch points and tube length. The branch points were 402.21 \pm 15.93 branches $/ \mathrm{mm}^{2}$ in the Epo B group and $388.50 \pm 24.68$ branches $/ \mathrm{mm}^{2}$ in the control group. The number of branch points in the Epo B group was higher than that in the control group (increased by 1.03-fold). The tube length in the Epo B group was increased by 1.08-fold compared with that in the control group. However, there was no significant difference between these two group ( $p>0.05, n=6$; Fig. S4), which was consistent with the results in vivo. These results suggest that Epo B could not promote lumenogenesis. Together these results suggest that microtubule stabilization promotes cell proliferation and inhibits apoptosis but does not promote lumenogenesis.

\section{Microtubule stabilization inhibits the migration of endothelial cells and pericytes}

To examine the migration response of endothelial cells and pericytes to microtubule stabilization, the transwell experiment was performed. The results showed that the migration of both endothelial cells and pericytes was significantly inhibited by Epo B. The number of migrated endothelial cells was $181.10 \pm 6.06$ cells $/ \mathrm{mm}^{2}$ in the control group and 129.50 \pm 7.89 cells $/ \mathrm{mm}^{2}$ in the Epo B group $(p<0.01, n=6$; Fig. $4 \mathrm{a}-$ b). The migrated pericytes were $476.60 \pm 28.65$ cells $/ \mathrm{mm}^{2}$ in the control group and $257.90 \pm 45.70$ cells $/ \mathrm{mm}^{2}$ in the Epo B group (reduction by $45.89 \%, p<0.01, n=6$; Fig. $4 \mathrm{c}-\mathrm{d}$ ). The results revealed that the migration of endothelial cells and pericytes was suppressed by microtubule stabilization.

\section{Microtubule stabilization upregulates expression of the angiogenesis related proteins}

VEGFA, VEGFR2, PDGFB, PDGFR $\beta$, Ang-1, and Tie-2 are essential in the initiation, formation, and functioning of blood vessels. To examine the effect of microtubule stabilization treatment on the expression of angiogenesis related molecules in vivo, the tissue obtained from SCI rats at 21-day post injury was collected and examined with western blotting. The results demonstrated that the expressions of VEGFA, VEGFR2, PDGFB, PDGFR $\beta$, and Ang-1 in the Epo B group were significantly increased by 2.16-, 2.00-, 1.79-, 2.28, and 2.23-fold compared with those in the vehicle group $(p<0.01, n=6$; Fig. $5 \mathrm{a}-\mathrm{f})$. The expression of Tie- 2 in the Epo B group was increased by 1.42 -fold but was not significantly different compared with that in the vehicle group ( $p>0.05, n=6$; Fig. $5 \mathrm{~g}$ ).

To examine the effects of microtubule stabilization treatment on the expression of angiogenesis related molecules in vitro, the expressions of VEGFA, VEGFR2, PDGFB, 
a
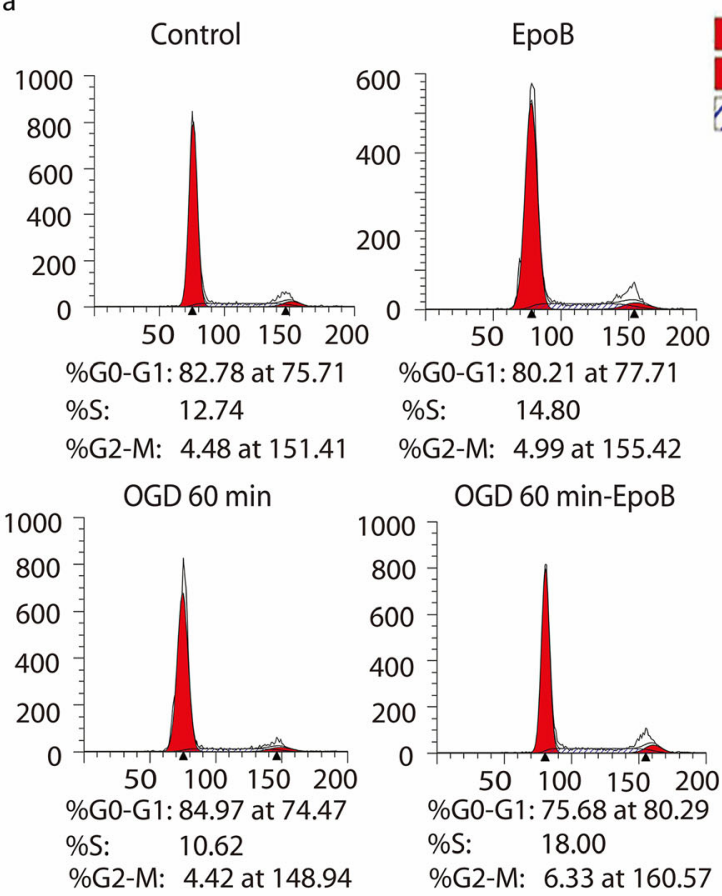

b

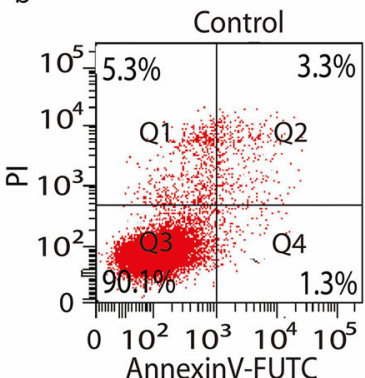

Dip GQ-G1

Dip G2-M

7/. DipS
C

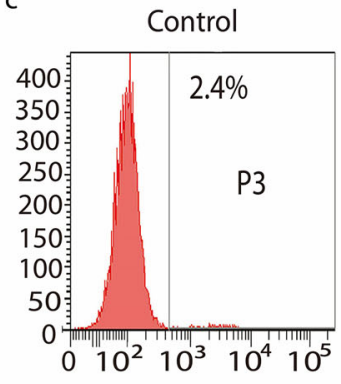

EDU

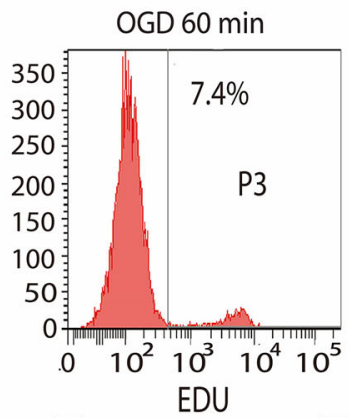

OGD $60 \mathrm{~min}$

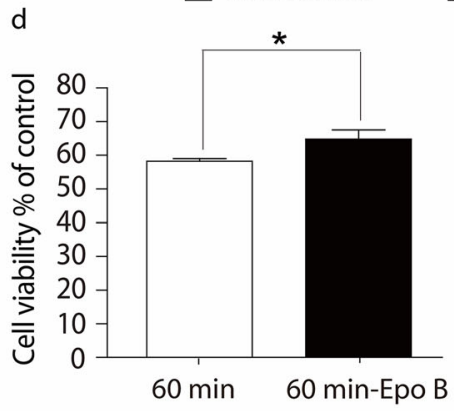

OGD $60 \mathrm{~min}$
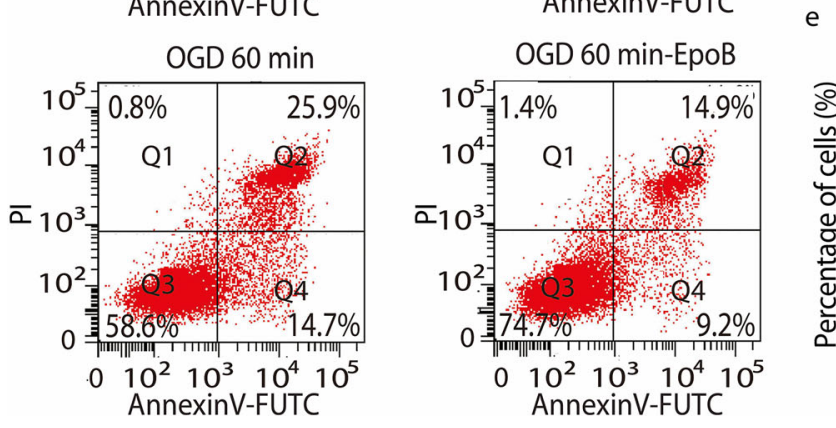

Fig. 3 Microtubule stabilization promotes cell proliferation and inhibits apoptosis in endothelial cells. a The cell cycle of endothelial cells in each group was determined by flow cytometry. b The endothelial cells apoptosis in each group was tested by flow cytometry. c The fluorescence intensity of EDU expressing endothelial cells in each group was measured by flow cytometry. $\mathbf{d}$ The viabilities of endothelial
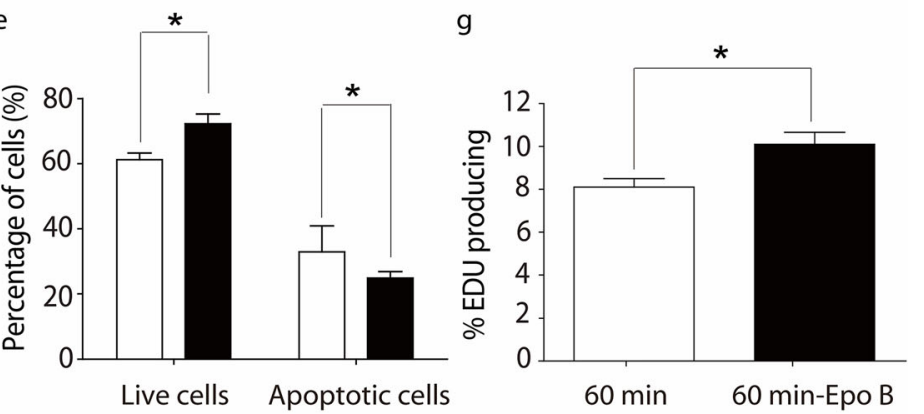

cells were analyzed by CCK- 8 assay. e Statistical analysis of the number of apoptosis of endothelial cells. f Statistical analysis of the number of endothelial cells in each phase in each group. $\mathbf{g}$ Statistical analysis of the fluorescence intensity of EDU expressing endothelial cells in each group. Results are expressed as mean $\pm \operatorname{SD}(n=6)$. $* p<0.05$. Significance is determined by student $\mathrm{t}$-tests.

PDGFR $\beta$, Ang-1, and Tie-2 in endothelial cells and pericytes under the OGD condition treated with or without Epo B were examined. Even that OGD alone increase angiogenesis related proteins (Freitas-Andrade et al. 2008; Gao et al. 2020; Ulleras et al. 2001), the expressions of all these six proteins were more upregulated in both endothelial cells and pericytes treated with Epo B. Similar to the results from the SCI rats, the expressions of VEGFA, VEGFR2, PDGFB, PDGFR $\beta$, and Ang-1 were significantly upregulated in the OGD 60-min Epo B group compared with those in the OGD 60 min group $(p<0.01, n$ $=6$; Fig. $5 \mathrm{~h}-\mathrm{j}$ and $1-n)$. Consistent with the results of the in vivo experiments, the expression of Tie-2 showed no significant difference between the OGD 60-min and the OGD 60-min Epo B group ( $p>0.05, n=6$; Fig. 5k). These data 
a

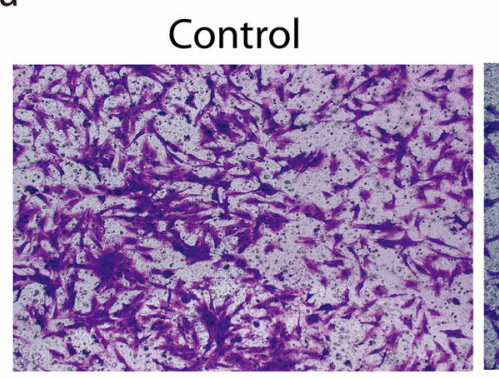

C

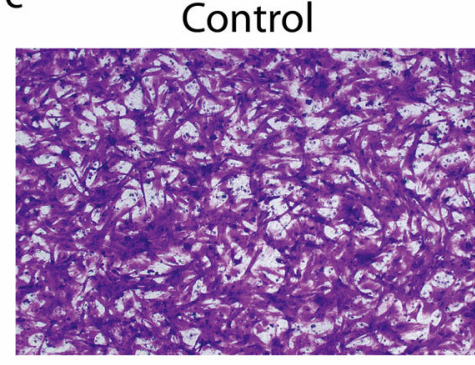

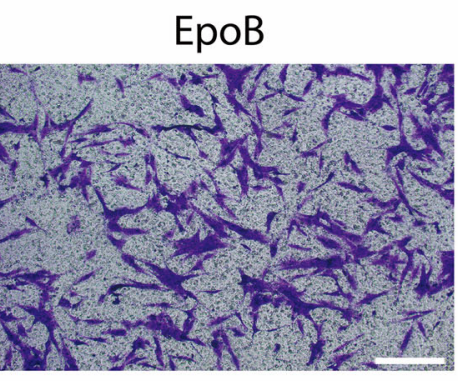

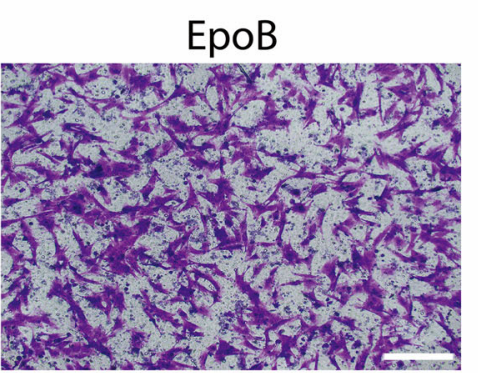

b
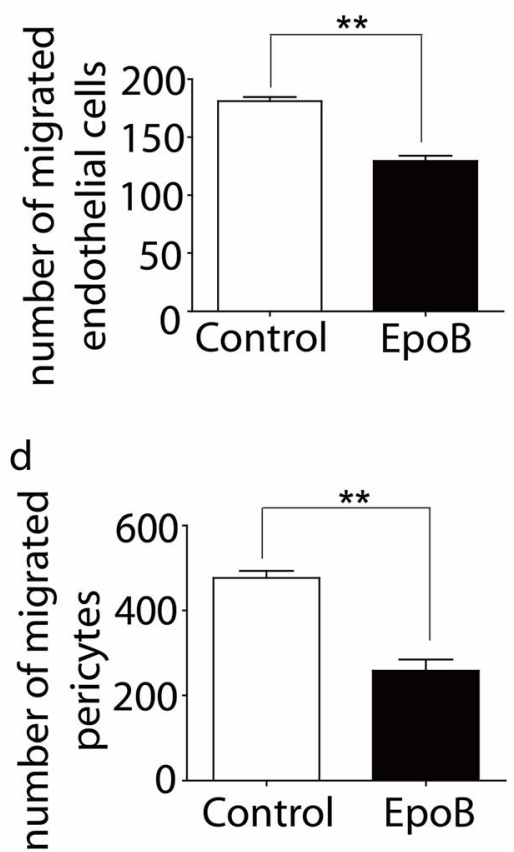

Fig. 4 Microtubule stabilization inhibits the migration of endothelial cells and pericytes. a Crystal violet staining of migrated endothelial cells. Scale bar: $25 \mu \mathrm{m}$. b Statistical analysis of migrated numbers of endothelial cells. c Crystal violet staining of migrated pericytes. Scale bar: $25 \mu \mathrm{m}$. d
Statistical analysis migrated numbers of pericytes. Results were expressed as mean $\pm \operatorname{SD}(n=6)$. $* * p<0.01$. Significance was determined by student $\mathrm{t}$-tests. reveal that VEGFA, VEGFR2, PDGFB, PDGFR $\beta$, and Ang1 may be involved in the process of restoration of the microvessels induced by microtubule stabilization treatment.

\section{Discussion}

Our study identifies a novel mechanism by which microtubule stabilization exerts protective effects against microvasculature dysfunction in SCI. Our findings suggest that microtubule stabilization protects microcirculation by inhibiting the apoptosis and migration of endothelial cells and pericytes and promoting proliferation of endothelial cells and pericytes, which may be related to the upregulation of VEGFA, VEGFR2, PDGFRB, PDGFR $\beta$, and Ang-1.

The destruction of microcirculation after SCI leads to ischemia and hypoxia in the local injury site, which contributes to neuron apoptosis, astrocyte necrosis, and scar formation. These serious pathological and physiological changes create a microenvironment which is unfavorable for nerve regeneration. Microcirculation reconstruction is one of the key factors of nerve regeneration. The major components of microvessels are endothelial cells and pericytes (Armulik et al. 2005). Various physiological activities of cells, such as cell division, proliferation, apoptosis, necrosis, and migration are affected by altering the microtubule structure and expression. Epo B is a microtubule stabilizing anti-cancer drug, which promotes the polymerization of tubulin heterodimer into microtubule polymers (Altmann 2003). It is demonstrated that the microtubules of scar-forming fibroblasts and neurons were stabilized by Epo B. However, the effect of Epo B on endothelial cells and pericytes still remains unclear. Our study showed OGD induced breaking and fragmentation of microtubules of endothelial cells and pericytes in a time-dependent manner, but after treatment with Epo B, the endothelial cells and pericytes were more stabilized, organized, and exhibited less disruption of the microtubules. Therefore, in this study, we focused on the effects of microtubules stabilization induced by Epo B on the microcirculation reconstruction after SCI.

Microtubules are one of the components of the cytoskeleton. Microtubules are involved in cell migration, organelles transportation, and chromosome segregation during mitosis and cell fate determination (Goodson and Jonasson 2018). Microtubule disruption can lead to a series of adverse consequences, such as insufficient transportation of intracellular material, disturbance in the formation of intercellular gap junction and the dysfunction of mitochondria, which result in irreversible damage of the cells (Devillard et al. 2006). Stabilization of the microtubules with taxol has been suggested to protect against hypoxia/re-oxygenation injury, while the microtubule depolymerizer, colchicine, has been reported to abolish the protective effect of ischemic pre-conditioning (Hu et al. 2010). The above-mentioned physical activities orchestrated by microtubule are essential in initiation, formation, 


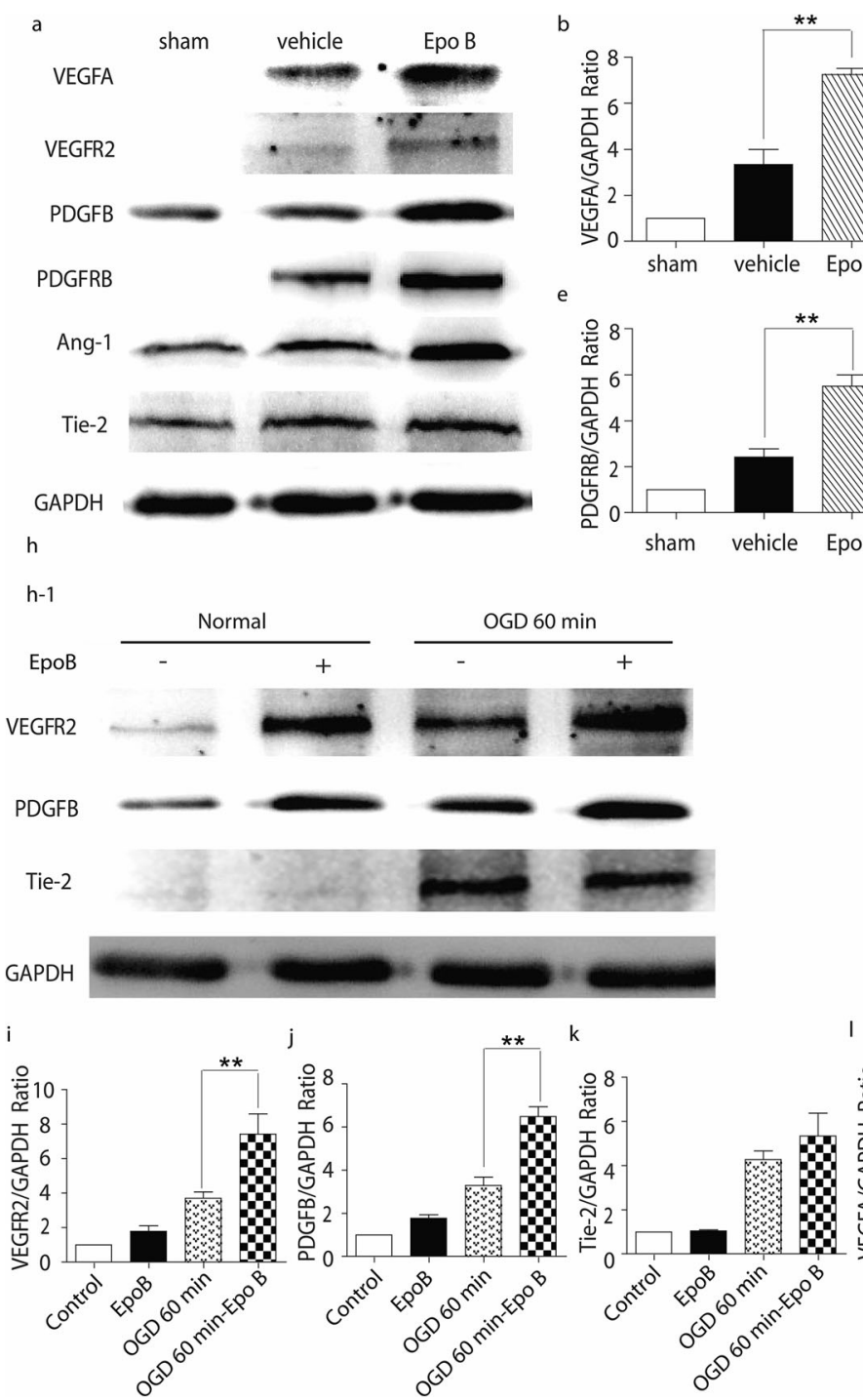

Fig. 5 Microtubule stabilization upregulates the expression of angiogenesis related proteins. a Immunoblotting analysis of the expressions of VEGFA, VEGFR2, PDGFB, PDGFR $\beta$, Ang- 1 and Tie2 in three groups of SCI rats. b-g Statistical analysis of the relative intensity of VEGFA, VEGFR2, PDGFB, PDGFR $\beta$, Ang- 1 , and Tie-2 in SCI rats. h-1 Immunoblotting analysis of the expressions of VEGFR2, PDGFB, and Tie-2 in endothelial cells in four groups. h-2

and maturation in angiogenesis. Endothelial cells are the main component of the microvasculature and are responsible for establishing direction and developing tubular structures. Pericytes then invade the newly vascularized tissues and localize at the growing front of the endothelial sprouts. Pericytes ensure that the newly formed vessel is mature, functional and stabilized by regulating the vesicle transport and bulk flow transcytosis, upregulating the endothelial tight junction protein, and moderating the tight junctional alignment (Jo et al. 2013; Nehls et al. 1992). In this study, the pericytes and microvessels, especially functionally perfused microvessels, were increased by microtubule stabilization treatment. Furthermore, the motor function of hind limbs of SCI rats
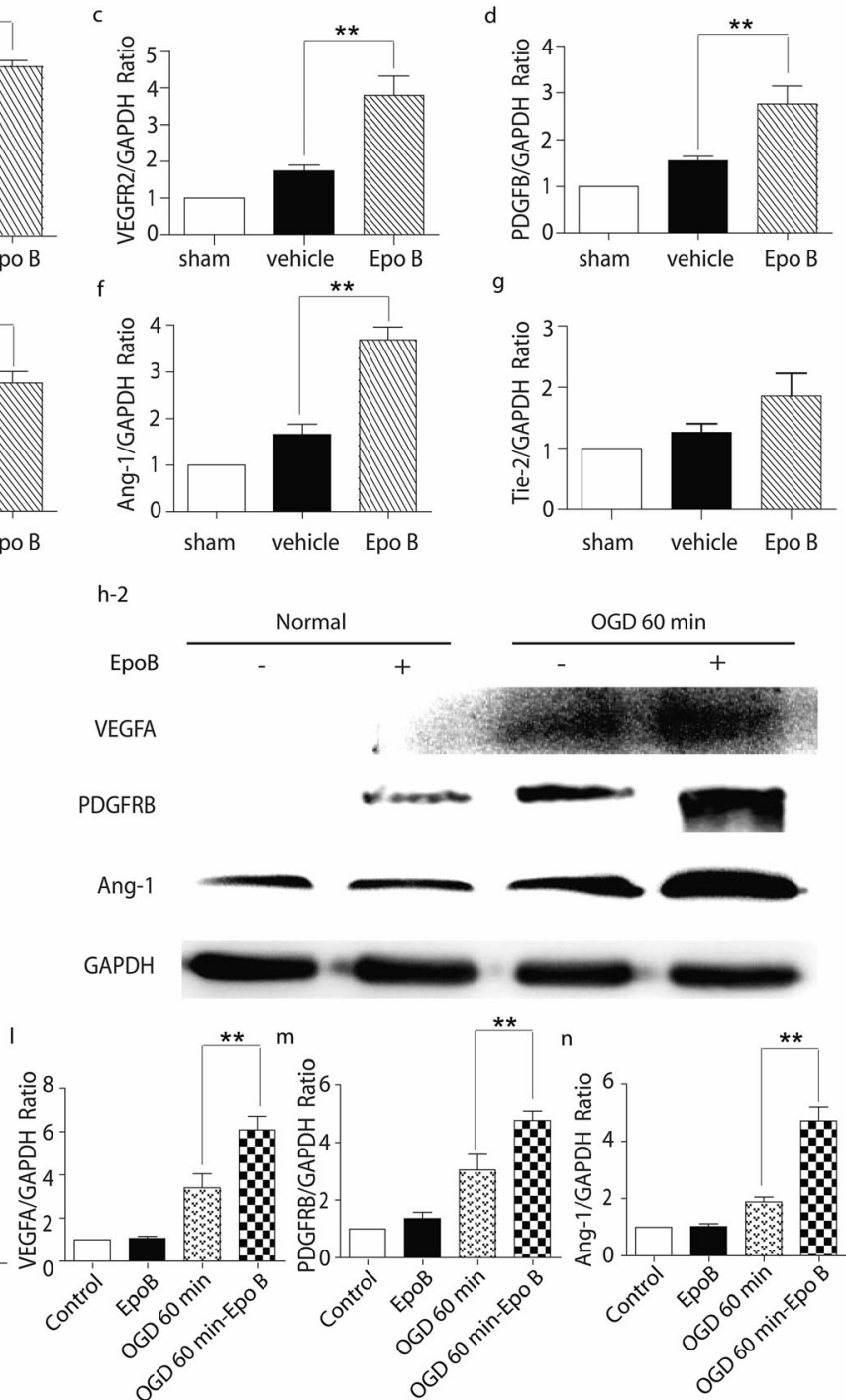

Immunoblotting analysis of the expressions of VEGFA, PDGFR $\beta$, and Ang-1 in pericytes in four groups. $\mathbf{i}-\mathbf{k}$ Statistical analysis of the relative intensity of VEGFR2, PDGFB, and Tie-2 in endothelial cells in four groups. I-n Statistical analysis of the relative intensity of VEGFA, PDGFR $\beta$, and Ang-1 in pericytes in four groups. Results are expressed as mean $\pm \mathrm{SD}(n=6)$. $* * p<0.01$. Significance is determined by one-way ANOVA followed by LSD comparison tests.

was significantly recovered after microtubule stabilization treatment (Fig. S2). Microtubule stabilization is required for formation and maintenance of angiogenic structures (Bayless and Johnson 2011). A stable microtubule network in endothelial cells secures vesicle trafficking to apical membranes to provide nutrition and drive vessel formation (de Forges et al. 2012; Norden et al. 2016). The inflammation-induced endothelial barrier dysfunction was rescued by microtubule stabilization after acute lung injury ( $\mathrm{Li}$ et al. 2015). In addition, the stabilized microtubule in pericytes maintained microvasculature function ( $\mathrm{Li}$ et al. 2017b). Some studies have shown that the loss of pericytes leads to endothelial hyperplasia and dysfunction and the coverage of pericytes in microvessels 
contributes to the vasculature regeneration (Hellstrom et al. 2001; Lu et al. 2019). Therefore, once the vasculature establishes, the microtubule network must remain intact and stabilized to maintain a regular angiogenic network (de Forges et al. 2012). Taken together, microtubule stabilization treatment could promote microcirculation reconstruction, which is favorable for axon regeneration to improve functional recovery after SCI.

Lumenogenesis is an initial and fundamental process in microcirculation regeneration. It has been reported that the stable microtubules of endothelial cells promote lumenogenesis and sufficient tissue reperfusion after ischemic injury by upregulating expression of acetylated and detyrosinated tubulins (Kim et al. 2013; Li et al. 2017a). However, lumenogenesis was not affected by microtubule stabilization in this study as our results revealed that the acetylated tubulin in endothelial cells was not upregulated by microtubule stabilization treatment (Data not shown). This result could be explained by the use of Epo B, which only modifies the structure of microtubule, but does not alter the acetylation of microtubules. Furthermore, during lumen formation, endothelial cells are separated into tip cells and stalk cells. The former is responsible for sprouting and establishing direction, while the latter proliferate, migrate, follow the tip cells, and differentiate to form the lumen (Duran et al. 2017). Our results indicated that the migration of endothelial cells was inhibited by microtubule stabilization treatment. The physical cell migration is induced by a very precise regulation of microtubule dynamic at the leading edge, and the microtubule catastrophe is also essential at the cells' leading edges (Drabek et al. 2006; Niethammer et al. 2004). Both are required to maintain a rapid turnover of focal adhesions, which allows for rapid and efficient migration (de Forges et al. 2012). However, in this study, the microtubule was stabilized by Epo B, which inhibited the microtubule catastrophe at the cells' leading edges, and consequently inhibited the cell migration. Collectively, our results suggested that the microtubule stabilization treatment may promote microvascular regeneration via the proliferation of stalk cells.

VEGFA, VEGFR2, PDGFB, PDGFR $\beta$, Ang-1, and Tie-2 play an essential role in microcirculation reconstruction. VEGFA is expressed in pericytes and its receptor, VEGFR2, is expressed in endothelial cells (Duran et al. 2017). Their interaction promotes cell survival and proliferation via increasing the expression of anti-apoptotic Bcl-2 and survivin (Sweeney et al. 2016). Consistent with this, our research showed that VEGFA and VEGFR2 were up-regulated in the Epo B-treated group in vivo and in vitro and the apoptosis of endothelial cells was inhibited by microtubule stabilization treatment. However, the survival and proliferation of endothelial cells were increased by microtubule stabilization treatment. In addition, combined VEGF and PDGFB treatment reduces secondary degeneration by promoting angiogenesis after SCI (Lutton et al. 2012). VEGFA binding to VEGFR2 upregulates PDGFB expression in pericytes, thereby promotes binding to its receptor, PDGFR $\beta$. The binding of these molecules facilitates proliferation and inhibits apoptosis. Consistent with those studies, in this study, PDGFB and PDGFR $\beta$ were upregulated in the Epo B-treated group in vivo and in vitro, the apoptosis of pericytes was decreased, and their survival and proliferation were promoted by microtubule stabilization. Activation of the PI3K pathway by PDGFB-PDGFR $\beta$ promotes actin reorganization, stimulates cell growth, and reduces cell apoptosis $(\mathrm{Hu}$ et al. 1995). PDGFB- or PDGFR $\beta$-null mice die at midgestation from cardiovascular defects. These embryos show abnormal angiogenesis and their blood vessels have poorly organized basement membranes and decreased coverage of pericytes (Armulik et al. 2005). In vivo, our results showed that the loss of pericytes coverage was decreased by microtubule stabilization at 2 day post injury. In vitro, we demonstrated that the migration of pericytes was inhibited by microtubule stabilization. Moreover, the interaction of the above molecules upregulated Ang-1 in pericytes through a cascade of reactions with its receptor Tie-2, which is expressed in endothelial cells (Jain 2003). Their interaction acts on plus end proteins to facilitate microtubule polymerization, which is indispensable for vessel stabilization and maturation (Armulik et al. 2005; Sweeney et al. 2016). This study demonstrated that Ang-1 was upregulated in the Epo B-treated group in vivo and in vitro, but Tie-2 was not upregulated. Recently, Savant $\mathrm{S}$ et al. have indicated that Tie-1 counter-regulated Tie-2 cell surface presentation and sustained Tie- 2 signaling and cell survival in remolding of endothelial cells (Savant et al. 2015). The expressions of orphan receptor Tie-1 are increased in tip cells, which results in the elevated Tie-2 being neutralized. This explains why Tie-2 was not enhanced by microtubule stabilization treatment. The specific mechanisms need to be investigated further. Importantly, the results from this study demonstrated that VEGFA, VEGFR2, PDGFB, PDGFR $\beta$, and Ang-1 are involved in the effect of microtubule stabilization on microvessel regeneration after SCI.

In this study, we demonstrated that microtubule stabilization protects microvessels and promotes the restoration of microcirculation. This study provides evidence of the potential use of microtubule stabilization as a therapeutic target to reduce microcirculation dysfunction after SCI in the clinic. In addition, it indicates a novel theoretical basis for the tissue engineering, such as adding to microtubule stabilizers or removing of microtubule destabilizers. 
Acknowledgements The authors thank Dr Fuzi Jin from the LunenfeldTanenbaum Research Institute (Toronto, ON, Canada) for thoroughly reading and revising the manuscript.

Funding This review was supported by the Natural Science Foundation of Shandong Province (no. ZR2017LH035) and Key Research and Development Program of Shandong Province (2019GSF107069).

\section{Compliance with ethical standards}

Conflict of interest The authors declare that they have no conflict of interest.

Open Access This article is licensed under a Creative Commons Attribution 4.0 International License, which permits use, sharing, adaptation, distribution and reproduction in any medium or format, as long as you give appropriate credit to the original author(s) and the source, provide a link to the Creative Commons licence, and indicate if changes were made. The images or other third party material in this article are included in the article's Creative Commons licence, unless indicated otherwise in a credit line to the material. If material is not included in the article's Creative Commons licence and your intended use is not permitted by statutory regulation or exceeds the permitted use, you will need to obtain permission directly from the copyright holder. To view a copy of this licence, visit http://creativecommons.org/licenses/by/4.0/.

\section{References}

Altmann KH (2003) Epothilone B and its analogs - a new family of anticancer agents. Mini-Rev Med Chem 3:149-158. https://doi. org/10.2174/1389557033405269

Armulik A, Abramsson A, Betsholtz C (2005) Endothelial/pericyte interactions. Circ Res 97:512-523. https://doi.org/10.1161/01.RES. 0000182903.16652.d7

Ballatore C, Brunden KR, Huryn DM, Trojanowski JQ, Lee VM, Smith AB 3rd (2012) Microtubule stabilizing agents as potential treatment for Alzheimer's disease and related neurodegenerative tauopathies. J Med Chem 55:8979-8996. https://doi.org/10.1021/jm301079z

Bayless KJ, Davis GE (2004) Microtubule depolymerization rapidly collapses capillary tube networks in vitro and angiogenic vessels in vivo through the small GTPase Rho. J Biol Chem 279:1168611695. https://doi.org/10.1074/jbc.M308373200

Bayless KJ, Johnson GA (2011) Role of the cytoskeleton in formation and maintenance of angiogenic sprouts. J Vasc Res 48:369-385. https://doi.org/10.1159/000324751

Benton RL, Maddie MA, Dincman TA, Hagg T, Whittemore SR (2009) Transcriptional activation of endothelial cells by TGFbeta coincides with acute microvascular plasticity following focal spinal cord ischaemia/reperfusion injury ASN Neuro 1. https://doi.org/10. 1042/an20090008

de Forges H, Bouissou A, Perez F (2012) Interplay between microtubule dynamics and intracellular organization. Int J Biochem Cell Biol 44: 266-274. https://doi.org/10.1016/j.biocel.2011.11.009

Devillard L, Vandroux D, Tissier C, Brochot A, Voisin S, Rochette L, Athias P (2006) Tubulin ligands suggest a microtubule-NADPH oxidase relationship in postischemic cardiomyocytes. Eur J Pharmacol 548:64-73. https://doi.org/10.1016/j.ejphar.2006.08.004

Drabek K et al (2006) Role of CLASP2 in microtubule stabilization and the regulation of persistent motility. Curr Biol 16:2259-2264. https://doi.org/10.1016/j.cub.2006.09.065
Dray C, Rougon G, Debarbieux F (2009) Quantitative analysis by in vivo imaging of the dynamics of vascular and axonal networks in injured mouse spinal cord. Proc Natl Acad Sci U S A 106:9459-9464. https://doi.org/10.1073/pnas.0900222106

Duran CL, Howell DW, Dave JM, Smith RL, Torrie ME, Essner JJ, Bayless KJ (2017) Molecular Regulation of Sprouting Angiogenesis. Compr Physiol 8:153-235. https://doi.org/10.1002/ cphy.c160048

Fitch MT, Silver J (2008) CNS injury, glial scars, and inflammation: Inhibitory extracellular matrices and regeneration failure. Exp Neurol 209:294-301. https://doi.org/10.1016/j.expneurol.2007.05. 014

Freitas-Andrade M, Carmeliet P, Stanimirovic DB, Moreno M (2008) VEGFR-2-mediated increased proliferation and survival in response to oxygen and glucose deprivation in PlGF knockout astrocytes. J Neurochem 107:756-767. https://doi.org/10.1111/j.1471-4159. 2008.05660.x

Gao C, Zhang CC, Yang HX, Hao YN (2020) MALAT1 Protected the angiogenesis function of human brain microvascular endothelial cells (HBMECs) Under oxygen glucose deprivation/reoxygenation $(\mathrm{OGD} / \mathrm{R})$ challenge by interacting with miR-205-5p/ VEGFA Pathway. Neuroscience 435:135-145. https://doi.org/10. 1016/j.neuroscience.2020.03.027

Goodson HV, Jonasson EM (2018) Microtubules and microtubuleassociated proteins. Cold Spring Harb Perspect Biol 10. https://doi. org/10.1101/cshperspect.a022608

Han $\mathrm{S}$ et al (2010) Rescuing vasculature with intravenous angiopoietin-1 and alpha $\mathrm{v}$ beta 3 integrin peptide is protective after spinal cord injury. Brain 133:1026-1042. https://doi.org/10.1093/brain/awq034

Hellstrom M, Gerhardt H, Kalen M, Li X, Eriksson U, Wolburg H, Betsholtz C (2001) Lack of pericytes leads to endothelial hyperplasia and abnormal vascular morphogenesis. J Cell Biol 153:543-553. https://doi.org/10.1083/jcb.153.3.543

Hu Q, Klippel A, Muslin AJ, Fantl WJ, Williams LT (1995) Rasdependent induction of cellular responses by constitutively active phosphatidylinositol-3 kinase. Science 268:100-102. https://doi. org/10.1126/science.7701328

$\mathrm{Hu}$ JY et al (2010) The p38/MAPK pathway regulates microtubule polymerization through phosphorylation of MAP4 and Op18 in hypoxic cells. Cell Mol Life Sci 67:321-333. https://doi.org/10.1007/ s00018-009-0187-z

Jain RK (2003) Molecular regulation of vessel maturation. Nat Med 9: 685-693. https://doi.org/10.1038/nm0603-685

Jo DH, Kim JH, Heo JI, Kim JH, Cho CH (2013) Interaction between pericytes and endothelial cells leads to formation of tight junction in hyaloid vessels. Mol Cell 36:465-471. https://doi.org/10.1007/ s10059-013-0228-1

Kim DJ, Martinez-Lemus LA, Davis GE (2013) EB1, p150Glued, and Clasp1 control endothelial tubulogenesis through microtubule assembly, acetylation, and apical polarization. Blood 121:35213530. https://doi.org/10.1182/blood-2012-11-470179

$\mathrm{Li} \mathrm{L}$ et al (2015) P38/MAPK contributes to endothelial barrier dysfunction via MAP4 phosphorylation-dependent microtubule disassembly in inflammation-induced acute lung injury. Sci Rep 5:8895. https://doi.org/10.1038/srep08895

Li F, Sawada J, Komatsu M (2017a) R-Ras-Akt axis induces endothelial lumenogenesis and regulates the patency of regenerating vasculature. Nat Commun 8:1720. https://doi.org/10.1038/s41467-01701865-X

Li Y et al (2017b) Pericytes impair capillary blood flow and motor function after chronic spinal cord injury. Nat Med 23:733-741. https:// doi.org/10.1038/nm.4331

Ling X, Liu D (2007) Temporal and spatial profiles of cell loss after spinal cord injury: Reduction by a metalloporphyrin. J Neurosci Res 85:2175-2185. https://doi.org/10.1002/jnr.21362 
Liu XZ, Xu XM, Hu R, du C, Zhang SX, McDonald JW, Dong HX, Wu YJ, Fan GS, Jacquin MF, Hsu CY, Choi DW (1997) Neuronal and glial apoptosis after traumatic spinal cord injury. J Neurosci 17 : 5395-5406

Lu Y, Zhou Y, Zhang R, Wen L, Wu K, Li Y, Yao Y, Duan R, Jia Y (2019) Bone mesenchymal stem cell-derived extracellular vesicles promote recovery following spinal cord injury via improvement of the integrity of the blood-spinal cord barrier. Front Neurosci 13:209. https://doi.org/10.3389/fnins.2019.00209

Lutton C, Young YW, Williams R, Meedeniya AC, Mackay-Sim A, Goss B (2012) Combined VEGF and PDGF treatment reduces secondary degeneration after spinal cord injury. J Neurotrauma 29:957-970. https://doi.org/10.1089/neu.2010.1423

Mautes AE, Weinzierl MR, Donovan F, Noble LJ (2000) Vascular events after spinal cord injury: contribution to secondary pathogenesis. Phys Ther 80:673-687

Muradov JM, Ewan EE, Hagg T (2013) Dorsal column sensory axons degenerate due to impaired microvascular perfusion after spinal cord injury in rats. Exp Neurol 249:59-73. https://doi.org/10.1016/j. expneurol.2013.08.009

Nehls V, Denzer K, Drenckhahn D (1992) Pericyte involvement in capillary sprouting during angiogenesis in situ. Cell Tissue Res 270: 469-474. https://doi.org/10.1007/bf00645048

Niethammer P, Bastiaens P, Karsenti E (2004) Stathmin-tubulin interaction gradients in motile and mitotic cells. Science 303:1862-1866. https://doi.org/10.1126/science.1094108

Norden PR, Kim DJ, Barry DM, Cleaver OB, Davis GE (2016) Cdc42 and $\mathrm{k}$-Ras control endothelial tubulogenesis through apical membrane and cytoskeletal polarization: novel stimulatory roles for GTPase effectors, the small GTPases, Rac2 and Rap1b, and inhibitory influence of Arhgap31 and Rasa1. PLoS One 11:e0147758. https://doi.org/10.1371/journal.pone.0147758

Qiu J (2009) China Spinal Cord Injury Network: changes from within. Lancet Neurol 8:606-607. https://doi.org/10.1016/S1474-4422(09) 70162-0

Ruschel J, Bradke F (2018) Systemic administration of epothilone D improves functional recovery of walking after rat spinal cord contusion injury. Exp Neurol 306:243-249. https://doi.org/10. 1016/j.expneurol.2017.12.001

Ruschel J, Hellal F, Flynn KC, Dupraz S, Elliott DA, Tedeschi A, Bates M, Sliwinski C, Brook G, Dobrindt K, Peitz M, Brustle O, Norenberg MD, Blesch A, Weidner N, Bunge MB, Bixby JL, Bradke F (2015) Axonal regeneration. Systemic administration of epothilone B promotes axon regeneration after spinal cord injury. Science 348:347-352. https://doi.org/10.1126/science.aaa2958

Sandner B, Puttagunta R, Motsch M, Bradke F, Ruschel J, Blesch A, Weidner N (2018) Systemic epothilone D improves hindlimb function after spinal cord contusion injury in rats. Exp Neurol 306:250 259. https://doi.org/10.1016/j.expneurol.2018.01.018

Savant S et al (2015) The orphan receptor Tie1 controls angiogenesis and vascular remodeling by differentially regulating Tie 2 in tip and stalk cells. Cell Rep 12:1761-1773. https://doi.org/10.1016/j.celrep. 2015.08.024

Sweeney MD, Ayyadurai S, Zlokovic BV (2016) Pericytes of the neurovascular unit: key functions and signaling pathways. Nat Neurosci 19:771-783. https://doi.org/10.1038/nn.4288

Ulleras E, Wilcock A, Miller SJ, Franklin GC (2001) The sequential activation and repression of the human PDGF-B gene during chronic hypoxia reveals antagonistic roles for the depletion of oxygen and glucose. Growth Factors 19:233-245. https://doi.org/10.3109/ 08977190109001089

Varma AK, Das A, Gt W, Barry J, Vertegel AA, Ray SK, Banik NL (2013) Spinal cord injury: a review of current therapy, future treatments, and basic science. frontiers. Neurochem Res 38:895-905. https://doi.org/10.1007/s11064-013-0991-6

Zhou T et al (2019) Microvascular endothelial cells engulf myelin debris and promote macrophage recruitment and fibrosis after neural injury. Nat Neurosci 22:421-435. https://doi.org/10.1038/s41593-0180324-9

Publisher's Note Springer Nature remains neutral with regard to jurisdictional claims in published maps and institutional affiliations. 